\title{
TALES OF TWO GUBERNATORIAL TRANSITIONS: UNDERLYING SCRIPTS FOR PRESS COVERAGE OF POLITICAL EVENTS
}

\author{
Robert L. Savage \\ Diane D. Blair \\ (University of Arkansas, Fayetteville)
}

The election of a new chief executive creates a number of needs, especially for information, for all other participants in the political system. Thus, the transition period, as the incumbent makes way for a successor, is a crucial instance of a rhetorical situation,

a complex of persons, events, objects and relations presenting an actual or potential exigence which can be completely or partially removed of discourse, introduced into the situation, can so constrain human decision or action as to bring about the significant modification of the exigence (Bitzer, 1968:6).

Such discourse may be directly with the incoming chief executive for some key actors but for most others that discourse is mediated by channels of mass communication.

Given the crucial character of this frequently recurring rhetorical situation in the American political process, it is surprising that not only has little research attention been given to their rhetorical aspects, but executive transitions generally are not well studied. ${ }^{1}$ Morever, nearly all of these research reports are singular case studies. This report attempts to redress these shortcomings by examining the press coverage of two gubernatorial transitions, albeit both in a single state, Arkansas. Certainly, two transitions in one state constitute a very limited sample as a basis for generalizations. Still, we hope to make a significant start toward such generalizations as the two transitions represent distinctly different types of rhetorical situations for incoming governors.

The first transition (Type I) followed the election in 1978 of Bill Clinton, a Democrat, to succeed David Pryor, also a Democrat. The second transition (Type II) followed Clinton's defeat in 1980 by a Republican challenger, Frank White. Thus, these two transitions separated by only two years in a single state allow an opportunity to study the two classic situations of a change in the incumbent only, as well as a change in both incumbent and partisan affiliation. ${ }^{2}$ 


\section{Media Coverage of Gubernatorial Transitions}

Transitions are inevitably characterized by a hectic tempo: policy goals must be enunciated, key cabinet selections announced, legislative strategies devised, budgets studied, inaugural festivities planned and publicized. All this activity occurs, however, in a situation where the mantle of power has been lifted from the outgoing governor and is descending upon the governor-elect, but the scepter of power has not yet been conferred. In this governing hiatus the most casual remarks of the governorelect (and other key political actors) regarding programmatic preferences or administrative intentions may be seized upon as significant.

Is the rhetorical agenda of gubernatorial transition as reported by the media set by these key political actors, or is it established by media personnel? We cannot answer that question directly by looking to media content. However, we can address the question of whether or not there is an agenda for media coverage by examining that content for structure, an underlying script, that points to what is newsworthy.

Finn (1984; see also Dorsey, 1983) has pointed to the utility of this information-processing approach derived from research in cognitive psychology and artificial intelligence. However, he argues that news value is determined in large part by recognizing deviations from such scripts, defined as "stereotypical sequences of events." How are reporters to make such determinations if the sequence of events to be expected is characteristically ambiguous, as it is with a gubernatorial transition? Moreover, if a script can be determined for a given type of gubernatorial transition, can it be applied to other types of transitions?

Assuredly, journalists would recognize and no doubt devote much attention to certain gross deviations from the usual in gubernatorial transitions such as the appointment of a member of the opposition party to a key administrative post or the announcement of detailed plans for the inauguration within a few days after the election. But these are generally infrequent occurrences. The more common problem for media reporters and their gatekeepers is the determination of the relative news value of given transition events vis-a-vis other events, including other transition events. (That determination may well be hampered by the fact that many transition "events" are trial balloons floated by the incoming administration or even merely rumors disseminated by interested parties. Again, after all, the transition is very much a rhetorical situation.) Media decision makers are faced with the problems, then, of what must be reported, may 
be reported, or should be ignored in covering the transition. ${ }^{3}$ Since there is no journalistic handbook for covering such situations, media reporters must look elsewhere for guidance.

\section{Social Science Literature on Transitions as a Guidepost}

We do not intend to argue here that journalists regularly look to the social sciences for scripting their reporting efforts. At the same time, social scientists may uncover (and even propagate) the stereotypical sequences of events that come to be associated with public practice. To that extent, then, social science (and related) literature is worthy of examination for the present purpose.

The problem is that the literature on gubernatorial transitions so often varies in the basic assumptions about the purpose or goals of a transition period. These variations depend largely upon the perspective adopted as to who is to be benefitted or impacted upon by the transition. The National Governors Association, in a how-to handbook for new governors, for example, makes the following suggestion:

If a Governor wants to be remembered at the end of his term for having accomplished certain things, then those things must be identified early in the term so that they can in fact be accomplished and so the Governor can be associated with their accomplishment. (Governing the American States, 1978: 144).

That is the gubernatorial perspective.

Norton Long (1972:84), from the perspective of other participants in a state's political system, describes the fundamental function of the governor-elect to be that of uncertainty absorption. Emphasizing the anxietyladen nature of this period for a state's political actors, Long suggests the prime necessity of a clear gubernatorial definition of the new governing situation:

Friends and foes alike demand that he define the situation so that the players may know the nature of the game being played. Even the adversary cooperation of the opposition requires that he set a target for them to shoot at. The press insists that he furnish a score card consisting of his musts so they can report the game.

Whereas both of the above formulations stress the systemic need of stability and continuity, Beyle and Wickman (1972) and Ahlberg and Moynihan (1972) have stressed instead the difficulty and importance of 
impressing change upon an innovation-resistant governmental structure. As Beyle and Wickman (1972: 91-2) note:

Incrementalism in personnel and policy change, budget constraints, entrenched habits of the old administration, and narrowly defined bureaucratic norms--all these factors contribute to what might be called systemic inertia ... So while the very term transition denotes change, perhaps the greatest challenge to the incoming governor is one of inducing change.

There is another possible characterization, surprisingly absent from the political science literature to date, the perspective of the responsible political parties doctrine. It has frequently been noted that the great achievement of political parties has been that of operationalizing the idea of democracy into a peaceful equivalent of revolution. Through a vigorous contest between those in power defining their achievements, and the vehement criticism of those out of office wishing to get in, the issues are publicized, the public informed, the choices presented in manageable form to the electorate. Elections, according to this conception, represent a legitimate overthrow of government. Through party competition the power struggle inevitable within the political system is stabilized and institutionalized.

Employing this conception, the transition represents a reluctant but peaceful surrender by those who have lost power, a joyous but orderly takeover by those who have achieved it. Since all contestants are loyal to the system, those bested will provide sufficient cooperation to the "revolutionaries" as they assume their new tasks that the government itself will not collapse. Still, the parties remain political rivals, and thus the new government will be largely on its own in adjusting to the new situation of being the government instead of its critic.

Clearly, countless features of American political reality have always departed, in varying degrees over time and place, from the competitive, responsible doctrine. Still, this conception of the transfer of power is as apt as ever for rhetorical analysis of gubernatorial transitions since American politicians and journalists have traditionally envisioned this as the proper, if not always the actual, mode for social change in a democratic society. Indeed, the notion has been reiterated so often over the past two centuries in this nation as to acquire the stature of political myth. As such, the notion of responsible party government provides a subliminal foundation for evaluating political phenomena (see Ninno and Combs, 1980), or put differently, an underlying script that provides guidance for understanding the pertinence and appropriateness of unfolding events. 
Assuredly, given the complex transactions among many actors during the transition period and the institutional needs of the mass media, e.g., meeting deadlines and staff availability, the actual presentations in the press may reflect other approaches to this recurring political phenomenon. Still, the responsible party doctrine provides the most comprehensive rationale of the transition process, and consequently, it is the richest source of hypotheses for testing.

For such testing we examine two recent gubernatorial transitions in Arkansas, the first of which involved an intra-party shift from Democrat to Democrat, the second and more recent involving a party turnover from Democrat to Republican. According to the responsible party ideal, these two types of transitions should display some distinctive differences. Since, as previously noted, transitions are essentially power vacuums in which rhetoric substitutes for actual governing authority, we test this mythic conception through analysis of what was communicated by and about the two governors-elect during their respective transitions.

\section{Procedures: The Data and Their Analysis}

The data were obtained by reviewing and coding all accounts of Clinton as governor-elect during the period November 6, 1978, through January 8, 1979, and all accounts of White as governor-elect during the period November 6, 1980, through January 13, 1981, in four Arkansas newspapers. Two of the newspapers are located in Little Rock and have statewide circulation. The other two are located in the northwest area of the state and are largely limited to a regional dissemination. Generally, the review used a code established by the authors before reading the newspaper items (see Table 2). ${ }^{4}$

Each author independently examined all items, encoding each category that appeared in a paragraph. No category was scored more than once per paragraph. Statements were also categorized as to source attribution: the governor-elect himself, other political leaders, editorial comment, and press background. Using the very conservative test, Scott's pi, intercoder reliabilities were 0.73 and 0.71 for the respective transitions, reasonable levels of agreement given the complexity of the code (see Holsti, 1969, 136-142).

\section{Hypotheses}

Using the responsible party doctrine, we offer a number of hypotheses which we believe will distinguish between the press coverage for a 
Type I (One-Party) Transition and that for a Type II (Two-Party) Transition. First, a Type II Transition should be characterized by far greater emphasis on public policy. This, after all, is the presumed essential purpose of throwing out one government and replacing it with another. The people have grown dissatisfied with the performance of the "ins" and have been attracted by the criticisms and alterative proposals of the challenger. In a Type II Transition, therefore, one should expect much more extensive discussion of the programs that will be mounted by the newly-chosen chief executive in response to a new popular mandate.

Second, there should also be a greater emphasis on personnel choices in a Type II Transition. It is also part of the ritualized exchange of power in a democratic system that a new leader will bring with him or her an entirely new cast of characters to assist in achieving the new objectives. Even with the moderation that civil service has imposed on the old spoils system, high-level officials will be replaced. New members of the cabinet, new staff personnel, new agency heads must all be chosen as part of the changing of the guard.

Third, since new policies can only be enacted by the legislature, we hypothesize much more discussion of executive-legislative relations in a Type II Transition. Only through skillful leadership of and bargaining with the members of the legislature will the new executive be able to fulfill the programmatic promises of the campaign, and these relationships may be especially problematic if the partisan makeup of the legislature is different from the newly-elected governor.

Fourth, a Type II Transition should also dwell more extensively on relationships with other governmental officials and organizations than would a Type I Transition. The entire political system must respond to this new governor and his/her associates, and the amount of cooperation or recalcitrance encountered will heavily impact upon the ability of the new regime to effectuate administrative change.

Fifth, we also hypothesize a greater concern with political parties and party organization in a Type II Transition. This, of course, reflects another aspect of what the election has accomplished. There is a new set of victors and vanquished; new roles must be learned, new positions staked out through the press to the public. Those accustomed to criticizing must learn to defend; those accustomed to explaining and defending must begin to gather ammunition for what will now be their assault upon the establishment.

A sixth hypothesis is that a Type II Transition coverage will contain fewer references to purely personal considerations. While a certain 
amount of biographical and behavioral information will be reported in any case, we expect much greater emphasis on such personalistic matters in a Type I Transition. In a Type I Transition, it is primarily the personal nature and style of the incumbents that is changing; in a Type II Transition, the voters presumably have mandated more fundamental changes in the very purpose of government.

A seventh hypothesis follows from the very underpinnings of the foregoing hypotheses. The differences between the two types of transitions flow from the presumed change in the character of the mandate passed by the voters to the Type II governor-elect. Since this is a more drastic change, we predict a stronger concern will be exhibited in a Type II Transition for ongoing popular support of the new regime.

Finally, flowing logically from all the above hypotheses, we expect much more press coverage for a Type II Transition. There is much more new information to be reported, speculated about, communicated to the actors in a political system and to the people who have set this new course of action in motion. Indeed, that a new party has captured the State House points to deviations from the past and marks subsequent events as all the more newsworthy.

\section{Findings}

In order to exhibit the corresponding relative treatments of the two transitions as economically as possible, we resort tc separate Q-factor analyses for the two transitions. As for each transition there are four attribution sources for each of four newspapers, a total of sixteen arrays of categorical treatment are available for each analysis. Using the eigenvalue-one criterion, only a single factor emerged in each instance, indicating a high degree of cohesion in descriptions across newspapers and across their sources of attribution. Table 1 presents the factor matrices (principal components) for both transitions.

The consistency of treatment of the Type II Transition is especially remarkable as the weakest correspondence to the basic underlying pattern still shows that the pattern explains about $64 \%$ of the variance in this case, White's own comments in Newspaper Alpha. This newspaper featured not only more direct quotes by the governor-elect generally but also extensive in-depth interviews that allowed him more freedom to expand upon topics than the forums available through the other newspapers.

In general, the greater consistency of treatment of the Type II Transition augurs well for our hypotheses since taken together they point to more 
Table 1. Factor Loadings for Separate Q-Factor Analyses of the Categorical Treatments By the Press of the

Clinton and White Transitions*

\begin{tabular}{llcc}
\hline \hline Newspaper & \multicolumn{1}{c}{ Source } & $\begin{array}{c}\text { Clinton's } \\
\text { Transition }\end{array}$ & $\begin{array}{c}\text { White's } \\
\text { Transition }\end{array}$ \\
Alpha & Self (Clinton or White) & 87 & 80 \\
& Other political leaders & 94 & 94 \\
& Editorial comments & 75 & 89 \\
& Press background & 87 & 85 \\
Beta & Self & 82 & 95 \\
& Other political leaders & 77 & 97 \\
& Editorial comments & 84 & 97 \\
& Press background & 83 & 90 \\
Gamma & Self & 77 & 94 \\
& Other political leaders & 65 & 94 \\
& Editorial comment & 72 & 92 \\
& Press background & 79 & 97 \\
Delta & Self & 88 & 94 \\
& Other political leaders & 54 & 94 \\
& Editorial comment & 84 & 92 \\
& Press background & 75 & 95 \\
& & & \\
& Percent of total variance & & 85.6 \\
\hline
\end{tabular}

*Decimals are omitted from loading factors

constraints in treatment than for the Type I Transition. Still, tests for most of the specific hypotheses require closer examination of the particular categories. Factor-score arrays presented in Table 2 show the relative weights of categories in press treatments of the two transitions. The results tend to support the hypotheses generally, but not without some qualifications.

Indeed, in relative weight of coverage, the first hypothesis is disconfirmed. Coverage of public policy positions in toto was about the same for both transitions. The difference lies in the heavier emphasis placed upon fiscal considerations during Transition II. In fact, on the average, the four 
Table 2. Factor-Score Arrays for Separate Q-Factor

Analyses of the Categorical Treatments

Category

Policy priorities

Programs: general

Programs: fiscal

Creation of positive feelings with

public or its involvement in decisions

Perception of electoral mandate and public support

View of self: biographical

View of self: behavioral

Relations with legislature

Relations with staff and cabinet

Relations with national government

Relations with local governments

Relations with other government organizations

Relations with Democratic

Party

Relations with Republican

Party

Relations with interest

groups

Transition and continuity

Inauguration

Miscellaneous
Clinton Transition Score Rank

$-0.6 \quad 11$

$1.8 \quad 2$

$2.9 \quad 1$

$-0.7 \quad 13$

$-0.7$

15

$0.3 \quad 5$

0.9

3

0.26

0.2

8

1.13

$-0.0$

7

0.54

1.1

2

$0.1 \quad 7$

0.4

4

$-0.1 \quad 8$

$-0.5$

11

$-0.8$

17

$-0.8$

18

$-0.8 \quad 15$

0.1

6

$-0.5 \quad 10$

$-0.7$

17

$\begin{array}{ll}-0.9 & 18\end{array}$

$-0.6$

13

$\begin{array}{ll}-0.7 & 14\end{array}$

$\begin{array}{ll}-0.3 & 10\end{array}$

$\begin{array}{ll}-0.3 & 9\end{array}$

$\begin{array}{ll}-0.3 & 9\end{array}$

$\begin{array}{ll}-0.6 & 12\end{array}$

$-0.7 \quad 14$

$-0.8 \quad 16$

$-0.6$

12

newspapers pointed to fiscal matters in nearly $25 \%$ of mentions devoted to transition coverage as opposed to just over $20 \%$ in Transition I. Moreover, the difference that does exist has no clear basis in the responsible party doctrine. White campaigned upon the basis of less government which 
meant both fiscal constraints on, and less expansion of, programmatic activities of government. As a consequence, policy considerations in Transition II were much more likely to reflect fiscal concerns. Indeed, given their different philosophies of government action, transitions to Republican administrations may generally be divergent from transitions to Democratic administrations in this regard.

Hypotheses 2, 3, and 4, regarding relations with other governmental actors, however, are all affirmed. Still, some cautionary remarks are called for. The stress upon legislative relations, despite the factor-analytic results, was actually not very different for the two transitions, averaging about $11.5 \%$ for Clinton and about $12.8 \%$ for White. The biennial presession budget hearings of the Arkansas Legislative Council, may however, be an important mitigating factor in lessening the impact of party change in transition coverage since much of that coverage is simply an outgrowth of press attention to the Council hearings. The incoming governor or his representatives are usually afforded ample opportunity to appear before the Council.

Hypotheses 2 and 4 are more strongly affirmed, particularly since personnel changes are involved in both areas. With regard to staff and cabinet this is very obviously the case. To amplify the factor-analytic results, the average percentages of mentions for staff and cabinet across the newspapers were 5.9 and 9.3 respectively. Personnel changes are also at issue with regard to other government organizations as many of these are boards and commissions for which the governor's control is limited largely to his appointment power which is a limited one indeed. These officials generally are appointed for specified terms that often overlap the governor's term of office. The press treatment in Transition II especially focused on personnel questions even in these agencies. The average coverage for the respective transitions were $1.5 \%$ and $7.1 \%$ respectively, a very substantial difference.

Surprisingly, then, there is only weak confirmation of the fifth hypothesis. Differences in coverage of political party relationships are not confirmed in the factor-analytic results and resorting to the relative coverage percentagewise (combining both Democratic and Republican Parties) shows only slight support for the hypothesis, 1.9 and 2.9 for the respective transitions.

The one aspect predicted under the party responsibility model to receive relatively greater coverage in the Type I Transition is that of personal qualities. Table 2 provides strong confirmation of this for both biographical and behavioral traits. This is even more apparent considering 
the relative volume of treatment percentagewise: combining the two categories and averaging across the four newspapers results in $19.4 \%$ for Clinton compared to only $9.2 \%$ for White.

The only other hypothesis relating to relative treatment of categories is only lightly confirmed by the factor-analytic results. This would be rather damaging to the party responsibility model as an explanatory factor if the electoral mandate is accorded similar weight in both types of transition. Reexamination of the data, however, shows that one newspaper (Delta) emphasized this element in the Clinton transition much more than the other three newspapers. Disregarding Delta, then, and combining both categories relating to popular involvement produces average percentage scores of 5.4 and 12.0 respectively, much stronger support of the hypothesis.

\section{Table 3. Volume of Treatment of Clinton (BC) and White (FW) Transitions \\ Four Newspapers}

\begin{tabular}{lccccccccc}
\hline \hline & \multicolumn{1}{c}{ Newspaper } & \multicolumn{2}{c}{} \\
Source & \multicolumn{1}{c}{ Alpha } & \multicolumn{3}{c}{ Beta } & Gamma & \multicolumn{2}{c}{ Delta } \\
& BC & FW & BC & FW & BC & FW & BC & FW \\
The Governor-Elect & 194 & 608 & 97 & 416 & 52 & 196 & 120 & 337 \\
$\begin{array}{l}\text { Other political } \\
\text { leaders }\end{array}$ & 19 & 380 & 89 & 547 & 3 & 153 & 12 & 288 \\
$\begin{array}{l}\text { Editorial } \\
\text { Press background }\end{array}$ & $\underline{356}$ & $\underline{1454}$ & $\underline{732}$ & $\underline{1445}$ & $\underline{99}$ & $\underline{710}$ & $\underline{172}$ & $\underline{1058}$ \\
Composite Total & 659 & 2579 & 1081 & 2815 & 188 & 1101 & 420 & 1972 \\
\hline
\end{tabular}

The final hypothesis simply asserts that a change in political parties will result in a considerably larger volume of transition coverage than where there is only a change of persons. As shown in Table 3, this hypothesis receives the strongest degree of confirmation. Breaking out the volume for the two transitions in terms of both the four newspapers and the four attribution sources shows more paragraphs devoted to the White transition in every cell, resulting in very large differences in the composite 
or total for all newspapers. The respective ratios for the four newspapers for the number of paragraphs devoted to the Type II Transition for each one devoted to the Type I Transition are: 3.9, 2.6, 5.9, and 4.7.

In general, then, seven of the eight hypotheses flowing from the application of the responsible party ideal to a comparative analysis of press coverage for two types of gubernatorial transition receive slight to very strong confirmation. In the discussion that follows an explanation is suggested as well as an exploration of the larger implications of the findings generally.

\section{Discussion}

Finding that the underlying script for press coverage of a gubernatorial transition involving a change in partisan control of the office appears to follow the responsible parties ideal does not mean that the political system itself is characterized by a party structure adhering to the responsible parties doctrine. Rather, it suggests that both political and media actors may more or less consciously fall back upon this mythic conception as a source of cues to guide them in what is a more stressful, perhaps even disorienting, situation than that occurring with a Type I Transition.

More than this, the finding suggests that the media, by falling back upon a standard model that points to a legitimate means of social change, acquire a paragovernmental role by assisting in the assurance of orderly continuity in the governmental system. That editorial commentary and press background categorizations of the transition are so similar to categorizations used by political actors further supports this contention. Assuredly, media people determine in part what statements by political actors are published. Still, where governor-elect White was allowed ample freedom to say what he wanted in Newspaper Beta, he varied from the overall pattern only by placing greater emphasis upon policy matters without fiscal considerations and by downplaying his relations with the state legislature (moving closer to the responsible party ideal on the one hand and further away on the other).

The major deviation from the responsible party conception was the lesser emphasis than expected upon public policy in the Type II Transition. However, we suspect that in reality a second factor intervened that may have produced greater policy emphasis in our case of Type I than would normally be expected and less in our Type II case than should be expected. Quite simply, the basic political philosophies, or more precisely, the orientations toward governmental action, of the two governors- 
elect contrasted with the change induced by partisan switch in incumbency. The representative for a Type I Transition, Bill Clinton, is a dedicated activist, whereas Frank White had a much more limited conception of appropriate government activity.

These differences in philosophical premises affected only the relative coverage of policy in the two transitions and thus provide only a modest qualification of the role the responsible parties ideal as an underlying script in press coverage of gubernatorial transitions. Indeed, given that political parties as candidate-recruiting, campaign-waging, fund-raising, and policy-making organizations probably have less consequential presence in Arkansas than in any other state, the general applicability of the mythic ideal here is as rigorous a test as can be constructed. ${ }^{5}$

Clearly, dimensions other than partisan affiliation may shape the character of gubernatorial transitions. Some obvious possibilities include the insider-outsider distinction, ideological or coalitional cleavages, and personality conflicts. Thus, where a governor-elect has presented himself/ herself as one outside the political establishment, personnel concerns might well take on greater importance even than in a Type II transition. Strong ideological conflict, whether in a Type I or Type II Transition would probably bring great emphasis to policy concerns. Coalitional conflict in a Type I Transition would likely heighten concerns for partisan relationships and perhaps for policy and personnel as well. Strong personality conflicts between incumbent and successor are probably less predictable given their idiosyncratic character. Whatever the nature of such conflicts, in all cases the volume of coverage is likely to be higher than for transitions of Type I where one old party hand passes the reins of government on to another partisan crony.

Press coverage of a transition, then, is a rhetorical situation of critical importance in a democratic polity whether the purpose of the transition is viewed as establishing order or continuity, building a governing majority, inducing policy change, and/or serving the political ambitions of the governor-elect. Such purposes, however, point more to the words and actions of political leaders in given contexts than to the recounting of the media. Journalists will no doubt be sensitive to whatever cleavages emerge among political leaders but will look to their underlying scripts for evaluating those conflicts. For transitions of chief executives, the responsible parties doctrine, a strong and enduring myth in American political life, is a very comfortable script for those in the journalistic enterprise. 


\section{Notes}

${ }^{1} \mathrm{~A}$ review of literature on presidential transitions is to be found in Lee et al. (1979), the first thoroughly study of this phenomenon from a rhetorical perspective. For a bibliography of the literature on gubernatorial transitions, see Beyle (1985: 459-461). The first rhetorical study of gubernatorial transitions was Blair and Savage (1980); see also Blair (1985) and Savage and Blair (1985).

${ }^{2}$ Actually, the most "stable" instance of a transition in opposition to one involving a change in party ties would be a same-party transition in a strongly commpetitive twoparty state, which Arkansas clearly is not. Still, if predictable differences in the two Arkansas transitions examined here do appear, then generalizations will be all the more warranted given the stronger test.

${ }^{3}$ As it happens, press releases from the governor-elect and his/her transition teams are often transmitted virtually verbatim, usually intermediately through the wire services, but by no means are all these releases disseminated by the media, either partially or totally. Interestingly, such reports are not always flagged as to their source; this practice, intentional or otherwise, deserves more examination from both an empirical and ethical standpoint.

${ }^{4}$ In large part this code followed the one devised by Lee, et al, (1979) in their study of the Carter presidential transition with certain additions made necessary by the obvious differences between a presidential and a governor.

${ }^{5}$ For extensive discussion of the relative weakness of political parties in contemporary Arkansas, see Blair (1988: 98-104).

\section{References}

Ahlberg, Clark D., and Daniel P. Moynihan. 1972. "Changing Governors - and Policies," pp. 95-104 in Thad L. Beyle and J. Olivers Williams (eds), The American Governor in Behavioral Perspective. New York: Harper and Row.

Beyle, Thad L. 1985. Ed., Gubernatorial Transitions, The 1982 Election. Durham, NC: Duke University Press.

Beyle, Thad L. and John E. Wickman. 1972. "Gubernatorial Transition in a One-Party Setting," pp. 86-92 in Thad L. Beyle and J. Oliver Williams (eds.), The American Governor in Behavioral Perspective. New York: Harper \& Row.

Bitzer, Lloyd. 1968. "The Rhetorical Situation." Philosophy and Rhetoric, 1:1-14.

Blair, Diane D. 1985. “Two Transitions in Arkansas, 1978 and 1982," pp. 92-122 in

Thad Beyle (ed), What Guides Governors in Transition. Durham, NC: Duke University Press.

Blair, Diane D. 1988. Arkansas Politics and Government: Do the People Rule? Lincoln, NE: University of Nebraska Press.

Blair, Diane Kincaid, and Robert L. Savage. 1980. "The Rhetorical Challenge of a Gubernatorial Transition: Constructing the Image of Statecraft." Presented at the Annual Conference of the International Communication Association, Acapulco, Mexico, May.

Dorsey, Gary. 1983. “An Information Processing Approach to News Value,” in H. Seth Finn. Social Science News Letter, 68: 86-92. 


\section{Robert L. Savage and Diane D. Blair}

Finn, Seth. 1984. "A Script Theory of News Value." Unpublished paper, Department of Radio, Television and Motion Pictures, University of North Carolina at Chapel Hill.

Governing the American States: A Handbook for New Governors. 1978. Washington, D.C.: National Govemors Association.

Holsti, Ole R. 1969. Content Analysis for the Social Sciences and Humanities. Reading, MA: Addison-Wesley, 1969.

Lee, David, et al. 1979. "The Rhetorical Challenge of the Carter Transition: To Build a Governing Majority" pp. 473-489 in Dan Nimmo (ed). Communication Yearbook 3. New Brunswick, NJ: Transaction Books.

Long, Norton. 1972. "After the Voting is Over" pp. 76-86 in Thad L. Beyle and J. Oliver Williams (eds), The American Governor in Behavioral Perspective. New York: Harper and Row.

Nimmo, Dan and James E. Combs. 1980. Subliminal Politics: Myths and Mythmakers in America. Englwood Cliffs, NJ: Prentice-Hall.

Savage, Robert L. and Diane D. Blair. 1985. "Constructing and Reconstructing the Image of Statecraft: The Rhetorical Challenges of Bill Clinton's Two Gubernatorial Transitions," in Keith R. Sanders, et al., (eds). Political Communication Yearbook 1984. Carbondale: Southern Illinois University Press. 